\title{
Entre familiarismo explícito y opcional: Cambios en el régimen de cuidados de infancia en Chile.
}

\author{
Between explicit and optional familialism. Shifts of childcare \\ regime in Chile
}

William Vera Rojas*

Cecilia Montes Maldonado**

Carina De La Barra Urquieta**

\begin{abstract}
Resumen
Durante la última década en Chile se aprecia un cambio en el patrón de provisión de cuidados en infancia, derivado de nuevas formas de organización familiar, el aumento de la participación femenina en el marcado laboral, una reducción en las tasas de fecundidad, nuevas políticas de cuidados infantiles, entre otros. A partir de un estudio de casos, el presente artículo analiza el régimen de cuidados en primera infancia en Chile, examinando tres mecanismos de provisión: servicios extra-familiares, trabajo intrafamiliar, y tiempo para el cuidado. Se estudian las transformaciones del patrón de cuidados aplicando las categorías de familiarismo, equidad de género y socioeconómica. El artículo sugiere que el modelo chileno transita desde un familiarismo explícito a uno opcional, donde la equidad de género presenta un maternalismo atenuado y la equidad socioeconómica es segmentada.
\end{abstract}

Palabras claves: cuidados en infancia; familiarismo; equidad de género; equidad socioeconómica; Chile

\footnotetext{
Abstract

During the last decade the Chilean pattern of childcare provision is changing due to the rise of female participation in the labor market, the fertility rates reduction, new forms of family organization, new social policies to care, among others. Based on a case study the

*Investigador Asociado, Pontificia Universidad Católica de Valparaíso, Chile.

PhD. Universidad de Friburgo, Suiza.

${ }^{*}$ Docente e investigadora del Instituto de Psicología Social, Facultad de Psicología, Universidad de la República, Uruguay. Doctoranda en Estudios de Género: Culturas, Sociedades y Políticas, Universidad Autónoma de Barcelona, España. Investigadora asociada del Sistema Nacional de Investigadores del Uruguay (SNI-ANII).

${ }^{* * *}$ Egresada de Sociología, Universidad de Valparaíso, Chile.
} 
article examines the childcare regime, analyzing three mechanisms of provision: extrafamily services, paid and unpaid family work, and time to care. It is analyzed changes in this childcare pattern by using the conceptual categories of familialism, gender and social equity. This paper suggests that the Chilean model shifts from an explicit to an optional one. The gender equity is characterized by a weak maternalist and the social equity is showed segmented.

Keywords: childcare; familialism; gender equity; social equity; Chile

Fecha de recepción: 12 de mayo 2017

Fecha de aprobación: 30 de mayo 2018

\section{Introducción}

Durante los últimos años existe en América Latina un gran debate sobre el tema de desigualdades de género, conciliación trabajo doméstico y remunerado, y cuidados. A nivel gubernamental la discusión recae sobre la necesidad de generar condiciones de mayor igualdad de oportunidades para las mujeres, quienes históricamente han ocupado una posición de desventaja en el mercado laboral y en el ámbito familiar, limitando sus posibilidades de pleno desarrollo y autonomía.

En este debate, los cuidados a niños, adultos mayores y personas con alguna discapacidad conforman un campo de creciente interés relacionado al debate sobre las desigualdades económicas, sociales y culturales presente en este tipo de actividades. Los trabajos de cuidado han sido ejercidos históricamente por la esfera familiar y dentro de ella por las mujeres. La desigual distribución de roles, recursos y tiempos que implica afecta las oportunidades socioeconómicas de las mujeres, y contribuye a reproducir las desigualdades de género. Este patrón, sin embargo, entra en una profunda disyuntiva si consideramos la serie de transformaciones a nivel organizacional y estructural familiar, de perfiles demográficos, roles y funciones de género y la creciente inserción de las mujeres en el mercado laboral, produciéndose un proceso de crisis del modelo tradicional de provisión de cuidados (Aguirre, 2007; Arriagada \& Todaro, 2012; Ullmann, Maldonado Valera \& Nieves Rico, 2014).

Recientes iniciativas gubernamentales intentan responder a estos nuevos escenarios, proponiéndose una mejor redistribución de responsabilidades entre los géneros y entre la esfera privada y pública. Destacan la creación del Sistema Nacional de Cuidado en Uruguay, la Red Nacional para el Cuidado en Costa Rica o los Servicios de Cuidado Infantil en Ecuador. En el caso chileno destaca la creación del sistema Chile Crece Contigo, la extensión de los permisos parentales y, recientemente, la mejora en las condiciones laborales de trabajadoras del ámbito doméstico (Batthyany, 2015; Bedregal, 2010). La academia también muestra un creciente interés en investigar este tema y sus 
efectos sobre la estructura de oportunidades (Filgueira, Gutiérrez, \& Papadópulos, 2011; Lopreite \& Macdonald, 2014; Sauma, 2012; Staab \& Gerhard, 2011).

El artículo estudia las transformaciones del modelo de provisión de cuidados a la primera infancia, en específico servicios de cuidados brindados por el sector público y privado; servicios de cuidados desarrollados al interior de hogar y mecanismos que otorgan tiempo para cuidar período 2003-2013¹. Interesa estudiar el régimen de cuidados como economía política que organiza la provisión de cuidados entre las esferas de Estado, familia, mercado y comunidad y sus implicancias en materia de equidad de género y socioeconómica. Realizamos un estudio de casos destinado a describir y examinar las transformaciones producidas en el patrón de provisión de cuidados en Chile para el período seleccionado, aplicando las categorías analíticas de variedades de familiarismo y tipos de equidad socioeconómica y de género (Blofield \& Martínez Franzoni, 2015; Leitner, 2003).

\section{Cuidados, variedades de familiarismo, y equidades de género y socioeconómica}

Los estudios de género han logrado evidenciar en mayor medida el carácter social e histórico de los cuidados, situándolo como una actividad que asigna roles y funciones no sólo en relación a la posición socioeconómica de las personas, sino también respecto al género. El representa una serie de actividades relacionadas estrechamente al ámbito del trabajo y se desarrollan fundamentalmente dentro del ámbito doméstico-familiar que, aunque no cuentan con el suficiente reconocimiento social, constituyen un trabajo central en la reproducción social y en brindar bienestar cotidiano a las personas. Desde una perspectiva más aplicada, Batthyany (2015) considera el cuidado como una acción o actividad orientada a brindar ayuda a las personas dependientes en el desarrollo y bienestar de su vida cotidiana, implicando una dimensión material, respecto a lo económico, pero también emocional (Torns, 2008).

Desde una mirada macro-social Daly y Lewis (2011) se proponen estudiar las formas de organización que las sociedades se dan para proveer recursos económicos y sociales para llevar adelante las labores de cuidado. Para ello proponen el concepto de "social care" para explicar las formas de producción, organización y asignación de recursos de cuidados dentro contextos sociales específicos. Si bien el cuidado contiene actividades y relaciones que actúan sobre las necesidades físicas y emocionales de las personas dependientes, también está conformado por los marcos normativos, económicos y sociales que orientan la asignación de estos recursos. El social care se inspira en el

\footnotetext{
${ }^{1}$ El criterio para determinar el período de análisis 2003-2013 se basó en la disponibilidad de datos ofrecidos por las fuentes analizados en el contexto de un proyecto de investigación que comparó los casos de Chile y Uruguay. En el presente artículo sólo se hace referencia al caso de Chile.
} 
enfoque de régimen de bienestar, estudiando la división de responsabilidades de las esferas proveedoras de bienestar (Estado-mercado-familia-comunidad) en el trabajo, responsabilidades y costos asociados a labores de cuidados. Aunque el enfoque de régimen de bienestar se limitó inicialmente a estudiar las articulaciones producidas entre las esferas del Estado y el mercado (Esping-Andersen, 2015), posteriores revisiones feministas ampliaron su perspectiva al ámbito privado y a las desigualdades de género, examinado la división de roles y funciones al interior de la esfera familiar y la importancia de las tareas domésticas y de cuidados como fuentes de producción de bienestar (O'Connor, Orloff \& Shaver, 1999; Orloff, 1993; Razavi, 2007).

El social care permite analizar cómo un determinado tipo de organización y provisión de recursos refuerza la función de la esfera familiar o, por el contrario, libera a esta esfera de tales responsabilidades. Para describir este proceso Esping-Andersen (2000) habla de familiarismo, referido a los mecanismos que refuerzan las obligaciones de cuidados dentro de la esfera familiar y desfamiliarismo cuando se descomprime a la familia de estas tareas. Ahora bien, entre familiarismo y desfamiliarismo se encuentran diversos regímenes, desde modelos más conservadores -que refuerzan el rol de la familia y las mujeres como principales proveedoras de cuidados-, hasta modelos que promueven políticas activas de desfamiliarización. Cada patrón actúa en función de los principios y mecanismos que guían este proceso (arreglos institucionales), produciendo efectos diferenciados sobre la estructura de desigualdades en su dimensión socioeconómica y de género (Martínez-Franzoni, 2008).

Con el objetivo de determinar el tipo de familiarismo que caracteriza a un régimen de bienestar, adoptamos la categoría analítica de variedades de familiarismo de Sigrid Leitner (2003), quien propone cuatro tipos ideales de familiarismo: a) familiarismo explícito (instrumentos de políticas que fortalecen el rol de la familia como proveedor de cuidado, sin alternativas a la provisión familiar); b) familiarismo opcional( la familia tiene un rol importante disponiendo de alternativas al menos parciales de servicios y apoyos al cuidado fuera del ámbito familiar); c) familiarismo implícito (no brinda soportes desfamiliarizadores de cuidado, ni acciones familiarizadoras); d) desfamiliarizador (mecanismos de traspaso de responsabilidades de cuidados desde la familia a otras esferas).

Dependiendo de los principios que orientan las políticas de cuidados, y de la forma que operan los instrumentos de política de cuidados aplicados en un determinado régimen de cuidados, las personas dispondrán de diferentes oportunidades para gestionar los cuidados según condiciones socioeconómicas y de género, configurando modelos de equidad que refuerzan o modifican las desigualdades. Para analizar los tipos de desigualdades promovidos, Blofield y Martínez (2015) proponen tipos ideales de equidad de género y socioeconómica que refuerzan o alteran estas desigualdades. La equidad de género se expresa en tres tipos: a) maternalista (políticas que refuerzan el rol de las mujeres como primeras y principales responsables del cuidado); b) piso maternalista (políticas que reconocen el rol de las mujeres en los primeros meses de vida del hijo); c) 
corresponsabilidad (políticas redistributivas entre hombres y mujeres). Para la equidad socioeconómica también proponen tres tipos analíticos: d) residual (mecanismos de provisión focalizados a población con determinadas carencias o necesidades); e) contributiva o corporativista (asignación de recursos y servicios en función del estatus laboral de las personas); f) ciudadano o de derecho (sistemas de provisión que asignan recursos en función del estatus ciudadano de las personas). Ambas dimensiones de la equidad se encuentran en un proceso de constante interacción que refuerza en uno u otro sentido las desigualdades.

\section{El régimen de cuidados chileno}

Acá revisamos brevemente la literatura que ha estudiado el régimen de bienestar chileno con perspectiva de género y énfasis en los cuidados. Entre éstos destacan el análisis de la organización del sistema de seguridad social que realizan Giménez (2003) y Sunkel (2007), ambos catalogando el sistema de seguridad social como conservador y familiarista, expresado en un sistema que refuerza el rol masculino como proveedor económico (breadwinner) y el femenino de protección del hogar (maternalista). En un estudio comparativo entre Chile y Uruguay, Pribble (2006) sostiene que el modelo chileno representa una variante del tipo tradicional con jefatura masculina fuerte, observado a través de los mecanismos de otorgamiento de derechos y fundamentos existentes en las políticas de asignaciones familiares y servicios de cuidados. Se concluye que Chile presenta grandes desigualdades entre hombres y mujeres, asociadas a una trayectoria política particular de reformas neoliberales ortodoxas y restrictivas en términos de igualdad de género durante la dictadura militar.

Un reciente estudio comparativo Chile y México sobre servicios de cuidados y educación en primera infancia, Staab y Gerhard (2011) examina desde la dimensión de género el programa Chile Crece Contigo implementado entre 2006-2010. Concluye que la ampliación de estos servicios a hogares de estratos pobres y vulnerables buscó promover principalmente oportunidades educativas más que una política activa de promoción del empleo femenino. Así, no se contempló explícitamente una promoción de la corresponsabilidad de los hombres en el cuidado, manteniendo el carácter residual de la política social. Sin embargo, posteriormente, Staab (2014) sostiene que el carácter maternalista, tradicional y liberal del régimen chileno experimenta cambios a partir de las reformas políticas aplicadas en el ámbito de los permisos parentales y de servicios de educación y cuidados en primera infancia. Se observa una leve reorientación hacia mayores grados de equidad y protección social, pero sin abandonar la herencia liberal del régimen. La autora destaca un leve proceso de variación desde un maternalismo privado del tipo liberal hacia un maternalismo público derivado de la mayor injerencia de la esfera estatal.

Las investigaciones muestran cambios importantes en la arquitectura de bienestar de Chile en cuidados. Sin embargo, falta precisar cómo este patrón de provisión modifica el 
peso de las esferas, influyendo en la configuración de un tipo de familiarismo (variedad), y sus efectos en materia de equidad de género y socioeconómica. Para lograr comprender estas transformaciones a nivel de régimen de cuidados examinamos en detalle tres modalidades de provisión de cuidados en infancia: servicios de cuidados a niños menores de 6 años, trabajo doméstico remunerado y no remunerado, e instrumentos que brindan tiempo a los padres para cuidar.

\section{Metodología}

El artículo se enmarca en el estudio de casos nacionales aplicado al campo de los regímenes de cuidados. El caso corresponde a Chile, país de ingreso medio-alto, con un alto desarrollo en sus sistemas de políticas sociales y buenos indicadores de desarrollo humano a nivel latinoamericano (Filgueira, 2007; Marcel \& Rivera, 2008).

El estudio de casos sistematiza más de 90 fuentes secundarias con tres tipologías: gubernamentales (Ministerios de Desarrollo Social, Educación y Trabajo), producción académica publicada en revistas científicas, e informes elaborados por organismos internacionales. Los materiales hallados respetan criterios de confiabilidad, pertinencia y vigencia de los datos. Así como también la cobertura geográfica y delimitación cronológica (período 2003-2013). Las fuentes estadísticas son parte de bases de datos de la Comisión Económica para América Latina y el Caribe (CEPAL) y de diversos organismos estatales chilenos.

Para caracterizar el régimen de cuidados, se analizan diferentes instrumentos de provisión de recursos de cuidados en infancia. En primer lugar, servicios de cuidados de primera infancia públicos y privados, examinando cobertura por edad, distribución socioeconómica, tipo de oferta. En segundo lugar, se analizan los servicios de cuidados que se desarrollan dentro del hogar, representados por el trabajo doméstico en el caso del trabajo remunerado y las personas ocupadas en labores de hogar no pagadas. En tercer lugar, se describen los recientes cambios legales aplicados a los permisos maternales, paternales y parentales, así como un análisis de resultados de la aplicación de esta reforma.

Las preguntas de investigación que guían este trabajo son: ¿Qué tipo de familiarismo está presente en el régimen de cuidados en infancia de Chile? ¿Qué tipos de equidad de género y económica encontramos para cada instrumento? ¿Qué transformaciones son posibles de apreciar en el régimen de cuidados en una década? De encontrar cambios, ¿qué factores permiten comprender estas transformaciones?

\section{Chile y sus recientes políticas públicas en cuidados}

El caso de Chile en materia de cuidados representa un país de interés dado las recientes modificaciones introducidas a nivel de política públicas orientadas a buscar una mayor 
conciliación entre la vida laboral y familiar, así como a disminuir las desigualdades socioeconómicas y de género que se derivan de estas actividades. A continuación, se describen brevemente las principales modificaciones introducidas en materia de políticas públicas orientadas a la conciliación del trabajo y la familia.

\section{Servicios de cuidados en primera infancia}

Para el cuidado en primera infancia encontramos tres instrumentos de política pública. El primero, Sistema Chile Crece Contigo, Ley №20.379 de 2006 (BCN, 2017) y que dispone de servicios de guarderías y jardines infantiles públicos y gratuitos a niños hasta 4 años dirigidos a familias de los tres primeros quintiles de ingresos y cuyas madres trabajan formal o informalmente, buscan trabajo o estudian. El programa facilita la conciliación entre trabajo-remunerado y cuidados, y su objetivo es desarrollar mayores oportunidades de desarrollo a la infancia (Staab, 2013). Además, existe una amplia oferta de servicios de atención privados autorizados y supervisados por una entidad pública.

Un segundo instrumento corresponde al "Derecho a Sala Cuna", mecanismo de servicios de cuidados a niños menores de 2 años, hijos de mujeres que trabajan en empresas que disponen de 20 o más empleadas. Esta modalidad está estipulada en el Código del Trabajo (MINTRAB, 2002) y obliga al empleador a pagar un servicio privado de guardería externo a la empresa o disponer de una guardería en la empresa para los hijos de sus trabajadoras. Este instrumento provee servicios de cuidados sólo a la madre trabajadora y no al padre, excluyendo a trabajadoras asalariadas de empresas más pequeñas, y también a trabajadores del sector informal o cuenta propia. Una reciente modificación de 2006 amplía este derecho a trabajadores varones del sector público si el servicio al que puede optar la madre no dispone de cupos.

Un tercer instrumento es la oferta de atención y educación en primera infancia a niños de 4-5 años, organizado en el sistema nacional de educación, con oferta pública municipal y estatal, instituciones privadas que reciben subvención pública e instituciones privadas sin subvención (Staab, 2013). En 2013 se dicta la ley № 20.710 (MINEDUC, 2013) que reforma la Constitución de la República para hacer obligatoria la enseñanza del kínder (56 años) y crea un sistema de gratuidad en la atención a partir de los 2 años. Esta reforma hasta la fecha no se ha traducido en reglamentos que permitan su aplicación efectiva.

\section{Trabajo doméstico remunerado}

Otro mecanismo de provisión de cuidados corresponde al trabajo doméstico remunerado que desempeñan fundamentalmente mujeres. En 2014 la ley №20.786 (MINTRAB, 2014) iguala las condiciones laborales de trabajadoras domésticas con asalariados del sector 
privado (igualación del salario mínimo al resto de los trabajadores), seguridad social, permisos maternales, vacaciones, entre otras. Estas medidas entraron en vigencia en noviembre de 2015, excluyéndose a trabajadoras domésticas que viven en el lugar de trabajo.

\section{Tiempo y dinero para el cuidado}

Un tercer instrumento destinado a otorgar tiempo y dinero a los miembros del hogar para cuidar corresponde a los permisos y subsidios maternales, paternales y compartidos para padre-madre (parentales). En Chile antes de la reforma al sistema de licencias -Ley №20.545 de 2011 (MINTRAB, 2011)- las mujeres tenían derecho a 6 semanas de permiso prenatal y 12 semanas de permiso postnatal subsidiados por el Estado, ampliándose a 24 semanas. Para el permiso paternal, antes del 2005 el hombre disponía 1 día de permiso pagado, ampliándose a 5 de licencia postnatal. En 2011 se introduce el permiso parental que permite a partir de la semana 13 del postnatal de la mujer, traspasar bajo su voluntad al hombre hasta 6 semanas de esta extensión. La mujer también puede ampliar la extensión de 12 a 18 semanas trabajando jornada parcial. El hombre puede hacer uso de 12 de las 18 semanas trabajando jornada parcial. Otro cambio importante es la ampliación del derecho de licencias maternales no sólo a asalariados, sino también a trabajadores temporales y cuenta propia (Lupica, 2015). Respecto al dinero para este tipo de licencias, los montos son financiados por el Estado y cubren salarios de quienes ejercen los permisos hasta 2.500 dólares mensuales.

\section{La evidencia empírica}

Presentamos los principales resultados del análisis del régimen de cuidados en infancia de Chile. Primero, se hace una descripción del contexto general de cuidados en infancia para el período estudiado (2003-2013). Segundo, se examina la provisión de servicios a primera infancia, revisando diversos tipos de servicios existentes, coberturas, distribución, entre otros. Tercero, se analizan los mecanismos de cuidados desarollados dentro del hogar, representados por el trabajo doméstico pagado y no pagado. Finalmente, se describen los mecanismos de tiempo para el cuidado como permisos maternales, paternales y parentales.

\section{El contexto de cuidados en infancia}

Un primer factor asociado al cuidado infantil corresponde a la demanda potencial. En Chile la población de 0-5 años con relación al total de la población disminuye de 9,4\% año 2003 (1.493.901 personas) a 8,4\% año 2013 (1.484.330 personas). El índice de autonomía, estimado a partir de la relación entre la población infantil (0-5 años) con la 
población femenina de 15- 65 años (potenciales cuidadoras) en una proporción uno a uno, aumenta de 3,6 (2003) a 4,2 (2013), tendencia explicada en parte por la constante disminución en la tasa de natalidad chilena (1,96 año 2002 y 1,82 año 2015) (INE, 2015a).

Un segundo factor, asociado al contexto del cuidado, es la participación de mujeres en el mercado laboral. En la medida que ésta aumenta, implica un menor número de mujeres disponibles en forma exclusiva al cuidado. La Tasa de Actividad Económica Femenina (TAEF) de 15 años y más creció de 41,5\% (2003) a 45,5\% (2013), ubicándose bajo el promedio de América Latina de 50,8 (2013). Ahora bien, la distribución de la TAEF varía según los ingresos: quintil I 31,6\%; quintil II 38,2\%; quintil III 47\%; quintil IV $53 \%$; quintil V $63,1 \%$ año 2013. Mientras la distancia en la TAEF entre el quintil $V$ y I en Chile es de 31,5 puntos, la distancia promedio en Latinoamérica es sólo de 24,2 puntos (CEPAL, 2015a).

Un tercer factor que merece análisis está asociado a transformaciones en las estructuras familiares. En Chile los hogares biparentales con hijos decrecen de $45 \%$ (2003) a 33,6\% (2013), inversamente a lo que sucede con los hogares monoparentales que aumentan de $9,5 \%(2003)$ a $14,5 \%$ (2013). Los hogares extensos y compuestos disminuyen levemente de $28,2 \%$ (2003) a $26,8 \%$ (2013). Al desagregar por quintiles de ingresos apreciamos que los hogares biparentales con hijos disminuyen en el quintil I de 59,9\% (2003) a 35,1\% (2013), y los hogares monoparentales aumentan de 10,2\% (2003) a 19,8\% (2013). Los hogares biparentales con hijos del quintil $V$ disminuyen de un $41,7 \%$ (2003) a 31,9\% (2013) y los hogares monoparentales crecen levemente desde 9\% (2003) a 10,5\% (2013). Los hogares monoparentales con jefatura femenina suben de $25,9 \%$ (2003) a $37,9 \%$ (2013) (CEPAL, 2015a).

Así, Chile enfrenta un escenario de cambios en su patrón de provisión de cuidados en infancia, donde existe una menor demanda relacionada con bajas tasas de natalidad y por otro lado, una menor disponibilidad de mujeres con dedicación exclusiva a cuidar. Sin embargo, estas modificaciones no se traducen necesariamente en un alza significativa de la TAEF.

\section{Servicios de cuidados y educación a la primera infancia}

Los servicios de cuidado y educación a primera infancia a niños y niñas de 0 a 5 años es uno de los componentes que permite caracterizar el régimen de cuidados. Estos servicios cumplen una importante función desfamiliarizadora al trasladar tareas de cuidados desde la esfera familiar hacia otras esferas de provisión (Estado-mercado-comunidad) (Leitner, 2003). Sin embargo, dependiendo de las características que presente esta provisión, sus efectos en términos de desfamiliarización, equidad de género y socioeconómica pueden variar.

En el caso chileno, uno de los instrumentos relacionados con la provisión estatal hasta los 4 años es el Sistema Chile Crece Contigo, política social desde 2006. Este sistema 
dispone de múltiples servicios a la infancia, como guarderías y jardines infantiles gratuitos dirigidos a familias de los tres primeros quintiles de ingresos y cuyas madres trabajan formal o informalmente, buscan trabajo o estudian. Con estatus de derecho desde 2009, se aprecia un aumento progresivo de cobertura desde 2005 al 2010, crecimiento que se estanca con posterioridad (Batthyany, 2015). Junto a la oferta pública, existe una significativa oferta de guarderías y jardines infantiles privados, propios del sistema mixto de provisión de educación en Chile.

La educación a la primera infancia para niños y niñas de 4-5 años se organiza dentro del Sistema Nacional de Educación, que dispone de oferta pública, municipal y estatal, instituciones privadas con y sin subvención. La Ley de Inclusión №20.845 de 2015, eliminó el copago, selección y lucro que existía en los establecimientos privados subvencionados, de manera que es posible afirmar que las diferencias entre educación pública y privada subvencionada en materias de condiciones y calidad disminuyeron, salvo en lo relacionado al tipo de agente proveedor, el primero a cargo del Estado y el segundo bajo responsabilidad de organizaciones privadas sin fines de lucro. Ambas modalidades representan más del $80 \%$ de la oferta educativa.

Gráfico 1. Porcentaje de cobertura preescolar según edades, año 2003 - 2013

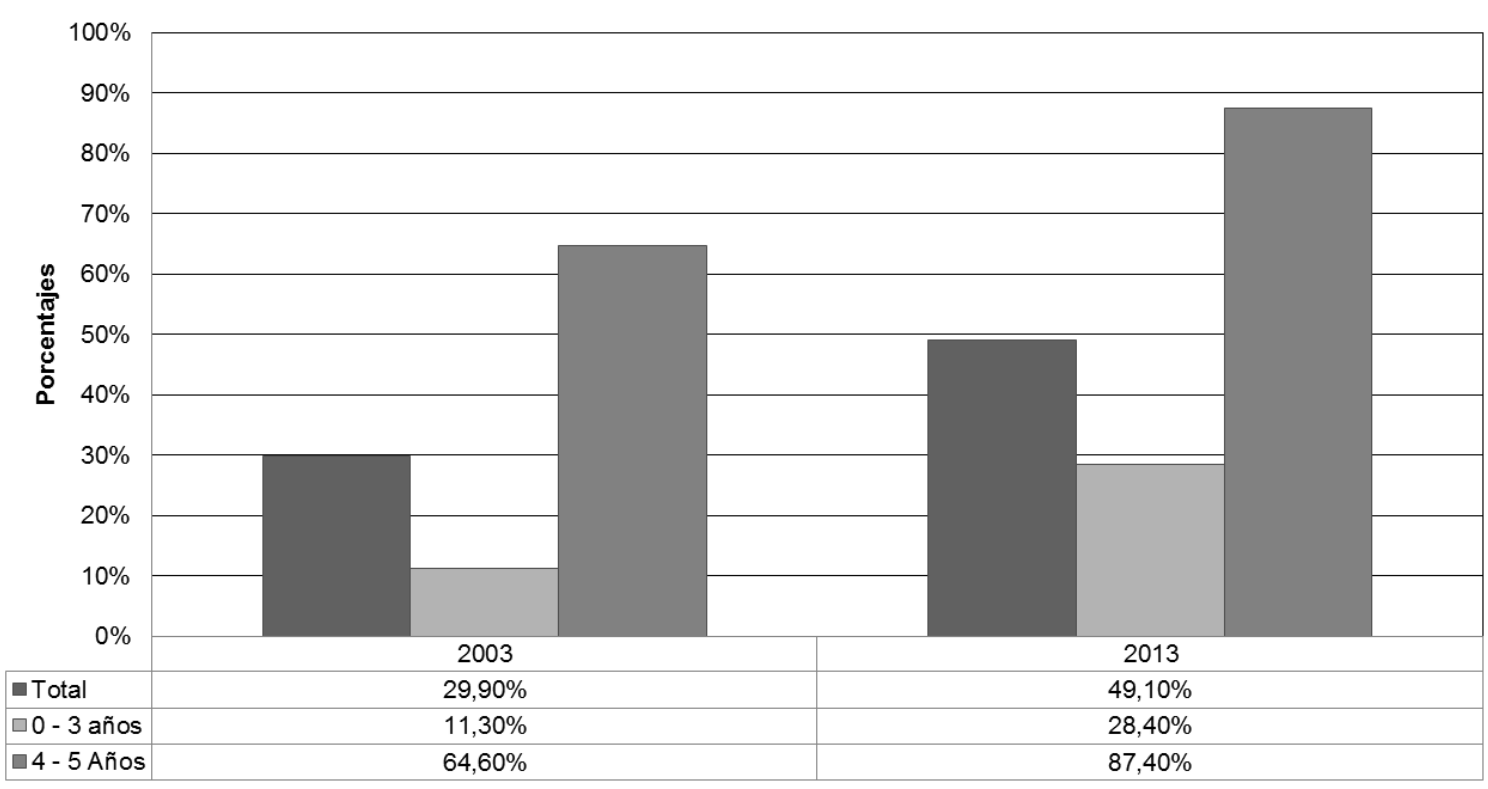

Fuente: Elaboración Propia, sobre la base de datos de CEPALSTAT

El gráfico 1 permite apreciar la evolución de la cobertura en educación preescolar (0-5 años) período 2003-2013, observándose una ampliación de ésta para el total de esta población desde un cercano 30\% (2003) a casi un 50\% (2013), incremento cercano a los 20 puntos en 10 años. Sin embargo, al distinguir por tramos de edad apreciamos importantes diferencias. Mientras el grupo de mayor edad (4-5 años) alcanza al año 2013 una cobertura casi universal de $87,40 \%$ (incremento cercano a 23 puntos en 10 años), el 
grupo de menor edad (0-3 años) aún no cubre un tercio del total de esta población, alcanzando una cobertura de $28,40 \%$ año 2013 (incremento de 17 puntos en 10 años).

La distribución de la cobertura de estos servicios ( $0-5$ años) por quintiles de ingresos año 2013 indican que la distancia entre el quintil I y $\mathrm{V}$ es de 9 puntos. Si se diferencian por tramos de edad, el grupo de 0-3 años el quintil I presenta un $24,4 \%$ y el quintil $V$ un $35,9 \%$ de cobertura, con una diferencia de 11,5 puntos. Para el tramo 4-5 años el quintil I representa un $85,9 \%$ y el quintil $\vee$ un $91,7 \%$ de cobertura, con una diferencia de 5,8 puntos. Estos datos permiten establecer que las mayores diferencias de cobertura por quintiles de ingresos se producen en el primer grupo de edad de 0-3 años (MDS, 2015a; MIDEPLAN, 2007). Al analizar la oferta de servicios de cuidados infancia (0-5 años) por tipo de proveedor para los años 2000, 2006 y 2013 se logra apreciar una relativa estabilidad entre la provisión pública y la privada. Cabe recordar que estas diferencias en materia de condiciones y calidad de los servicios de provisión entre la oferta pública y privada subvencionada deberían tender a atenuarse a partir de la reforma educacional del año 2015 antes referida, aspecto que este estudio no alcanza a incorporar.

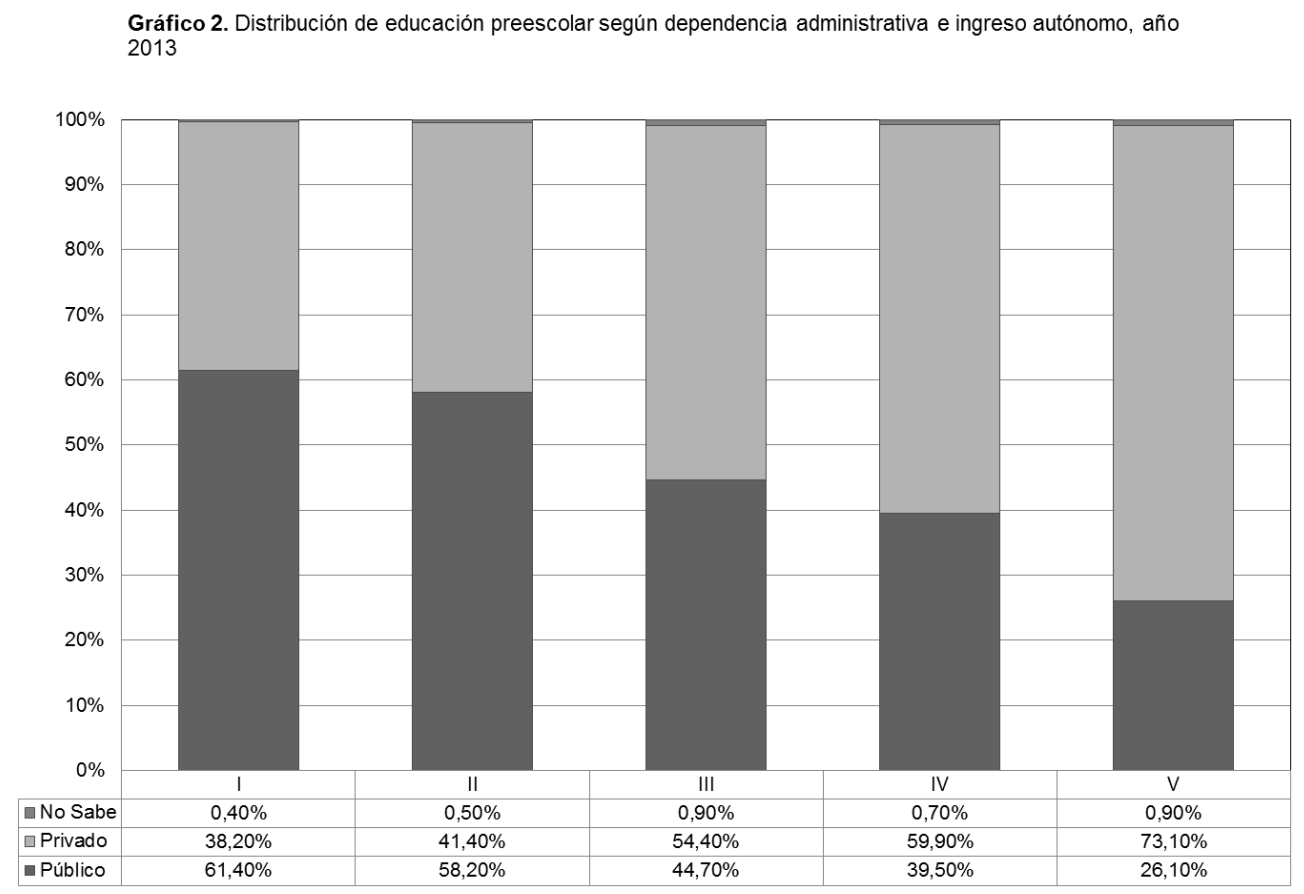

Fuente: Elaboración Propia, sobre la base de datos de CEPALSTAT

El gráfico 2 muestra la distribución de la cobertura por tipo de proveedor por quintiles de ingresos año 2013, observándose un decrecimiento en la provisión pública en la medida que aumentan los ingresos. Inversamente la provisión privada crece en la medida que los ingresos aumentan. La oferta privada es mayoritaria a partir del quintil III de ingresos y la oferta pública es mayoritaria en los quintiles I y II. 
En relación al mecanismo de provisión de servicios de cuidados a niños menores de 2 años provisto por aquellas empresas que disponen de 20 o más mujeres empleadas, norma establecida en el Código del Trabajo (DT, 2015), los datos de la Encuesta Laboral 2011 (ENCLA, 2012) muestran que de un total de 79.786 empresas encuestadas, sólo un $11,8 \%$ están obligadas a proveer este servicio. De ellas un $85,8 \%$ son grandes empresas, $39,8 \%$ son medianas y $6,2 \%$ son pequeñas. Del total de empresas con obligación $(11,8 \%)$, sólo en un $8,9 \%$ existen mujeres con hijos menores de 2 años. De esta última cifra, un $27,6 \%$ no cumple la normativa, siendo las empresas pequeñas quienes en mayor incumplimiento se encuentran. Estos resultados nos indican que la cobertura de cuidados mediante este instrumento legal es aún minoritaria, accediendo un pequeño número de trabajadoras asalariadas. El carácter de exclusión de este derecho a los hombres asalariados convierte a este mecanismo en un incentivo negativo para una mayor incorporación femenina al mercado laboral, puesto que los costos del cuidado siguen asociados sólo a las mujeres.

En síntesis, la significativa ampliación de la oferta de servicios de cuidados en primera infancia muestra un importante esfuerzo desfamiliarizador, pero con efectos diferenciados por edades. Para el grupo de 4-5 años la cobertura es cercana al $90 \%$, adquiriendo un carácter universal con alta desfamiliarización, en cambio para el grupo de 0-3 años de edad la cobertura aún no alcanza el 30\%, representando un proceso de desfamiliarización limitado.

El carácter mixto de provisión de estos servicios distribuido en partes iguales entre oferta pública y privada hace referencia un proceso de desfamiliarización vía estado (desmercantilización) y otra vía privados (mercantilización). Mientras que la primera, presenta oferta pública gratuita, su acceso está condicionado por criterios de comprobación de medios. En el caso del Sistema Chile Crece Contigo, aún cuando la oferta pública se amplía hasta el $60 \%$ de la población más pobre, persiste el carácter residual de la política social. Para la segunda modalidad de provisión mercantilizada su acceso está condicionado por la capacidad económica del hogar, por tanto, el patrón de provisión de cuidados combina rasgos residuales y mercantiles, propios del carácter liberal del régimen de bienestar chileno. La nueva ley de inclusión modificará en parte este rasgo, debido a que las familias que hacen uso de la oferta privada no podrán efectuar copagos para aumentar la subvención pública. Sin embargo, el sistema mantiene una modalidad de vouchers en que la familia puede elegir el establecimiento educativo, reforzando la segregación socioeconómica que caracteriza al sistema educativo.

En relación a la dimensión de equidad socioeconómica, apreciamos un modelo de provisión caracterizado por tres tipos de equidad en función de los tipos de mecanismos de provisión. Un tipo residual que organiza la provisión de servicios estatal en función de criterios de comprobación de medios hasta el quintil III de ingresos. La ampliación del criterio de ingresos desde el 40 al $60 \%$ más pobre muestra un proceso de transición desde una lógica residual a una ciudadana, pero condicionada aún a la capacidad del Estado de incrementar la cobertura pública. La modalidad de provisión de guarderías a 
mujeres trabajadoras (Derecho a Sala Cuna) se orienta por un tipo de equidad socioeconómica contributiva, puesto que el estatus salarial de las mujeres les otorga el derecho. Esta modalidad de cobertura limitada muestra la persistencia del rasgo corporativista en Chile, vinculado al estatus laboral de las mujeres. La tercera modalidad es la oferta privada, que representa una parte importante de la provisión de servicios de cuidados y educativos a la primera infancia. Antes de la ley de inclusión esta modalidad se organizaba en función de la capacidad económica del hogar, otorgando una equidad socioeconómica del tipo mercantilizada. Este carácter se eliminaría con la nueva ley debido a la prohibición del copago, pero podría persistir el problema de la segregación del sistema educativo.

En la dimensión equidad de género, apreciamos un patrón de provisión de cuidados con rasgos entre maternalismo tradicional y maternalismo atenuado, pero sin promover explícitamente corresponsabilidad masculina en cuidados. El carácter tradicional del maternalismo se aprecia en la mantención del derecho a sala cuna sólo a mujeres asalariadas, elemento que refuerza el rol tradicional de la mujer como responsable del cuidado, además de configurar un factor de discriminación laboral al desincentivar la incorporación de mujeres al mercado laboral asociado a los costos que supone para los empleadores su contratación, situación que no sucede con los hombres. El maternalismo atenuado se refleja en el caso chileno en el sistema Chile Crece Contigo, programa que ofrece servicios de cuidados a mujeres trabajadoras, que están buscando trabajo y estudiantes. Este programa tiene por objetivo facilitar la conciliación vida familiar y trabajo, representando un punto intermedio entre maternalismo y autonomía femenina. Por un lado, se busca incentivar el trabajo remunerado de las mujeres (autonomía), pero al mismo tiempo, exige a las mujeres una serie de labores de acompañamiento al cuidado de los hijos, sin promover explícitamente procesos de modificación estructurales de los roles de género y en la redistribución de las tareas entre sexos. El público objetivo de este programa son fundamentalmente las mujeres y no los hombres. Finalmente podemos decir que, debido a la desigual distribución de estos tipos de servicios entre estratos socioeconómicos, el patrón maternalista está más presente a nivel de estratos de ingresos bajos donde las tasas de coberturas son inferiores.

\section{Provisión de cuidados dentro del hogar}

Un segundo elemento de caracterización del régimen de cuidados en infancia se relaciona con la provisión de cuidados dentro del ámbito familiar del tipo no remunerado y remunerado. Una aproximación al volumen de mujeres dedicadas a las actividades no remuneradas está representada por la cantidad de mujeres encargadas de los quehaceres domésticos. 
Tabla 1. Situación de empleo población femenina por categoría ocupacional (porcentajes), años 20032013.

\begin{tabular}{|l|l|l|l|l|l|l|l|}
\hline Años & Ocupados & $\begin{array}{l}\text { Desocupad } \\
\text { os }\end{array}$ & Estudiantes & $\begin{array}{l}\text { Quehaceres } \\
\text { domésticos }\end{array}$ & $\begin{array}{l}\text { Jubilados y } \\
\text { rentistas }\end{array}$ & $\begin{array}{l}\text { Incapacida } \\
\text { d o } \\
\text { enfermedad }\end{array}$ & Otros \\
\hline $\mathbf{2 0 0 3}$ & 37,1 & 5,1 & 11,3 & 28,8 & 7,6 & 2,5 & 7,6 \\
\hline $\mathbf{2 0 0 6}$ & 39,2 & 4 & 11,6 & 15,1 & 8,6 & 4,3 & 17 \\
\hline $\mathbf{2 0 0 9}$ & 37,2 & 5,2 & 10,5 & 15,2 & 11 & 3,8 & 17,2 \\
\hline $\mathbf{2 0 1 1}$ & 39,3 & 4,2 & 11 & 18,6 & 12,5 & 3,5 & 10,8 \\
\hline $\mathbf{2 0 1 3}$ & 41,9 & 3,7 & 11 & 17,1 & 12,1 & 3,7 & 10,5 \\
\hline
\end{tabular}

Fuente: Elaboración propia en base a datos de CEPALSTAT

La tabla 1 muestra los cambios producidos en Chile en la situación laboral de mujeres de 15 años y más para el período 2003-2013. Mientras la población de mujeres ocupadas crece de $37 \%$ a casi $42 \%$ para el decenio, el grupo de mujeres dedicadas a quehaceres domésticos se reduce prácticamente en 12 puntos, de casi $29 \%$ a $17 \%$ para igual período (CEPAL, 2015b). Entre los motivos por el cual las mujeres expresan no dedicarse al trabajo remunerado citan razones de orden familiar permanente, entre las cuales se encuentran las actividades de cuidados según datos de la Encuesta Nacional de Empleos año 2013 (INE, 2015b). Según Betancor y De Martini (2012) en base a resultados de la Encuesta Voz de Mujer Bicentenario año 2010, observan que el grupo de mujeres con dos o más hijos menores de 14 años son quienes presentan menores tasas de actividad económica y mayores tasas de inactividad. Del total de mujeres inactivas consultadas, éstas indican que las principales razones que les impiden trabajar se encuentran los quehaceres domésticos y el no disponer de ayudas para cuidar. Dentro del grupo de mujeres inactivas con hijos menores de 14 años, las encuestadas señalan que la principal razón de su inactividad es no contar con alguien para dejar a los hijos. Estos datos expresan la incidencia del cuidado infantil en la participación de las mujeres en el mercado laboral.

Tabla 2. Mujeres con dedicación exclusiva a las labores del hogar, según posición de parentesco, con uno o más menores presentes en el hogar (porcentajes), años 2003-2013.

\begin{tabular}{|l|l|l|l|l|l|}
\hline Años & $\begin{array}{l}\text { Total mujeres de } \\
\mathbf{1 5} \text { años y más, }\end{array}$ & Jefa & Cónyuge & Hijas & $\begin{array}{l}\text { Otras (parientes } \\
\text { o no parientes) }\end{array}$ \\
\hline $\mathbf{2 0 0 3}$ & 32,7 & 22,3 & 46,9 & 14,5 & 24,7 \\
\hline $\mathbf{2 0 0 6}$ & 16 & 9,6 & 25,2 & 7,4 & 10,9 \\
\hline $\mathbf{2 0 0 9}$ & 16,4 & 10,2 & 27,8 & 6,8 & 10,1 \\
\hline
\end{tabular}




\begin{tabular}{|l|l|l|l|l|l|}
\hline $\mathbf{2 0 1 1}$ & 20,3 & 13,6 & 35,2 & 9,6 & 14,3 \\
\hline $\mathbf{2 0 1 3}$ & 18,1 & 12,9 & 30,3 & 7,6 & 13,5 \\
\hline
\end{tabular}

Fuente: Elaboración propia en base a datos de CEPALSTAT

Otro indicador de aproximación del volumen de la provisión de cuidados no remunerado dentro del hogar se muestra en la Tabla 2, indicando el porcentaje de mujeres dedicadas en forma exclusiva a labores domésticas en hogares con uno o más menores. La tabla señala que del total de mujeres de 15 años y más dedicadas a estas labores, existe una reducción de un 32,7\% a 18,1\% para el período estudiado, disminución cercana a 15 puntos. Las cónyuges son quienes más se dedican en forma exclusiva al hogar seguidas de las jefas de hogar y otros parientes.

Los datos muestran que el volumen de mujeres dedicadas al trabajo doméstico y de cuidados del tipo no remunerado se reduce significativamente para el decenio, disponiéndose de menor cantidad de mujeres ocupadas en forma exclusiva. Sin embargo, la reducción del trabajo de hogar no remunerado no está acompañado por un aumento significativo de la inserción femenina en el mercado laboral. La TAEF creció levemente para igual período de $41,5 \%$ a $45,5 \%$. Este indicador crece en la medida que aumentan los ingresos de las personas, por tanto, son las mujeres de menores ingresos quienes se dedican mayormente al trabajo doméstico y de cuidados no remunerados. La estimación del volumen de mujeres dedicadas exclusivamente al cuidado no remunerado no excluye del análisis la situación de aquellas mujeres que trabajando remuneradamente desarrollan en forma simultánea trabajo doméstico y cuidados, configurando la denominada doble jornada laboral.

El trabajo de cuidados dentro del hogar adquiere una forma remunerada, expresada en el trabajo doméstico pagado, actividad posible de estimar a través del volumen de mujeres ocupadas en servicios domésticos. La tabla 3 muestra una tendencia decreciente de este tipo de actividad para el período $2003-2011$, cayendo casi 4 puntos de $16,3 \%$ a $12,5 \%$.

Tabla 3. Estructura de la Población Ocupada (Mujeres) por categoría ocupacional (porcentajes), años 2003-2011.

\begin{tabular}{|l|l|l|l|l|l|}
\hline Años & Empleadores & Asalariados & $\begin{array}{l}\text { Cuenta } \\
\text { propia }\end{array}$ & $\begin{array}{l}\text { Servicio } \\
\text { doméstico }\end{array}$ & $\begin{array}{l}\text { Familiares } \\
\text { no } \\
\text { remunerados }\end{array}$ \\
\hline $\mathbf{2 0 0 3}$ & 3 & 61,1 & 17,1 & 16,3 & 2,5 \\
\hline $\mathbf{2 0 0 6}$ & 2,3 & 62,6 & 19,4 & 14,3 & 1,5 \\
\hline $\mathbf{2 0 0 9}$ & 2,3 & 65,8 & 19,2 & 12 & 0,6 \\
\hline $\mathbf{2 0 1 1}$ & 1,6 & 66 & 19,3 & 12,5 & 0,6 \\
\hline
\end{tabular}

Fuente: Elaboración propia en base a datos de CEPALSTAT

Esta leve reducción en la disponibilidad de mujeres dedicadas al trabajo doméstico y de cuidados remunerado debe al menos considerar dos factores asociados a este trabajo. 
Uno, es el aumento de la inmigración en Chile durante los últimos años, donde el trabajo doméstico representa una de las principales actividades económicas desarrollas por las mujeres inmigrantes. Dos, la promulgación reciente de la ley №20.786 que iguala condiciones laborales de las trabajadoras domésticas con el resto de los asalariados del sector privado. Estas medidas comienzan a aplicarse a partir de noviembre del 2015, pero excluyen a las trabajadoras domésticas puertas adentro (MINTRAB, 2014).

Sin embargo, estas cifras deben ser tomadas con cuidado, debido a que el sector del trabajo doméstico cuenta con un nivel importante de informalidad sumado a la participación de las mujeres migrantes que solventan gran parte de la demanda de cuidados (Orozco, 2007), debiendo tomar estas cifras con precaución. Estos elementos constituyen advertencias para los avances en la protección laboral. En la línea de las amenazas Molinier (2017) expresa que "el bienestar de unos no puede sostenerse sobre la servidumbre de otras, y el cuidado de los más vulnerables no debiera transformarse en una neo-domesticidad" (p. 342).

La modalidad de provisión de cuidados dentro del hogar muestra una disminución de mujeres dedicadas al trabajo doméstico no remunerado y remunerado, más acentuado en el primero que en el segundo. Respecto al primer tipo de provisión, su reducción implica una menor injerencia de la esfera familiar en tareas de cuidado. Respecto al segundo, implica una menor influencia de la esfera mercantil. Si agregamos además la disminución de población infantil menor de 5 años, estaríamos ante un escenario de cambio en el patrón de provisión tradicional existente, aunque estas modificaciones no están acompañadas necesariamente por un aumento significativo de la participación de las mujeres en el mercado laboral. Un segundo elemento se relaciona con la equidad socioeconómica; la reciente promulgación de ley que mejora las condiciones laborales de las trabajadoras domésticas supone un avance para este grupo de mujeres, mejorando salarios y condiciones laborales, pero junto a la amenaza de la neo-domesticidad. En materia de equidad de género este grupo de mujeres también fueron favorecidas al disponer de condiciones de protección a la maternidad similar al resto de las trabajadoras asalariadas, asumiendo la esfera estatal un rol central en la equiparación de oportunidades. Un tercer elemento atañe al aumento de la inmigración femenina dedicada al trabajo doméstico remunerado, sector probablemente menos protegido que las trabajadoras nacionales, configurándose un escenario de aumento de las desigualdades socioeconómicas y de género para este grupo en particular. Finalmente, si bien la disminución del trabajo de cuidados no remunerados y el aumento de la TAEF representan una mayor autonomía de las mujeres, la corresponsabilidad en las labores de cuidados dentro del hogar continúa recayendo en forma desigual en las mujeres, como lo indican las encuestas de uso del tiempo.

\section{Tiempo para el cuidado}


Un tercer componente de análisis del sistema de cuidados chileno corresponde a los mecanismos de tiempo para el cuidado, principalmente a través de los permisos legales maternales, paternales y parentales descritos anteriormente, destacando en general el aumento de los tiempos para el cuidado de recién nacidos.

Uno de los datos que permite analizar en parte este instrumento es el uso del permiso parental. Según datos de la Superintendencia de Seguridad Social (SUCESO, 2015), los subsidios correspondientes a este permiso (semana 13-24) para el período noviembre 2011-diciembre 2014 presentan un promedio mensual de subsidios iniciados de 8.174. Con la excepción de los dos primeros meses de aplicación de la nueva normativa, los subsidios incrementan anualmente de 6,3\% (2012-2013) y 6,2\% (2013-2014). El promedio mensual de trabajadoras cotizantes en edad fértil se incrementó de 1.300 .000 (2011) a 1.467 .467 (2014), con una variación del 4,3\%. Respecto al tipo de trabajadoras que acceden a este subsidio se establece que un $9,8 \%$ son dependientes del sector público, $87,8 \%$ dependientes del sector privado y sólo un $1,8 \%$ son independientes y en un $0,7 \%$ no se dispone de información.

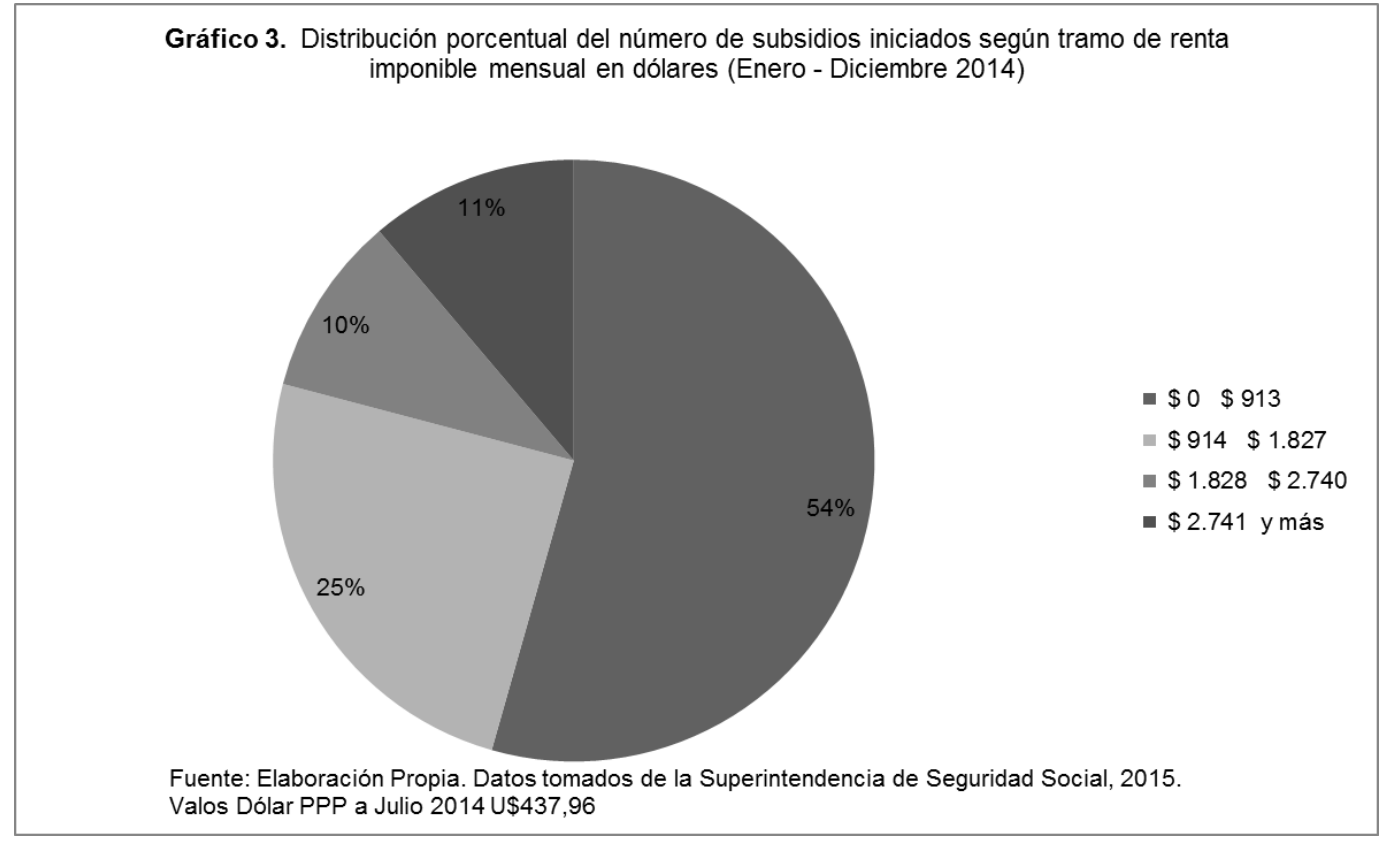

El gráfico 3 muestra la distribución de este subsidio por tramo de remuneración para el año 2014. El primer tramo de renta de 0 a 913 US dólares representa $54 \%$ de los subsidios iniciados; el segundo tramo de renta de 914 a 1.827 US dólar alcanza un 25\%; el tercer tramo de 1.828 a 2.740 US dólar corresponde al 10\%; el tramo de 2.741 y más US dólar representa el $11 \%$. Respecto al tipo de jornada laboral, un $98,3 \%$ de los subsidios iniciados correspondió a la modalidad jornada completa y sólo un 1,7\% modalidad jornada parcial período 2011-2014. De los subsidios pagados para el total del período, sólo un 0,26\% fue traspasado al padre. De éstos, un 95,5\% fue en modalidad jornada completa, utilizado fundamentalmente por padres con rentas del tramo de 
mayores ingresos. Respecto a rango de edad, los subsidios fueron iniciados por personas entre 20 y 40 años con un 82,1\% (SUCESO, 2015).

La ampliación de tiempo para el cuidado con protección del puesto de trabajo para el caso de madres y padres trabajadores representa un mecanismo que, si bien reubica la función de cuidado en la esfera familiar, al mismo tiempo protege el empleo de aquellas personas que ya están insertas en el mercado laboral, contribuyendo a reforzar su autonomía económica y facilitando que funciones productivas y reproductivas se concilien. Ahora bien, la extensión de la licencia maternal de 18-24 semanas, desde la perspectiva de equidad de género refuerza el maternalismo tradicional cuando no está acompañada de una extensión de la licencia paternal. Aunque en Chile aumenta los días de licencia paternal de 1-5 días, resulta insuficiente como incentivo para una mayor corresponsabilidad al compararlo con el tiempo de uso exclusivo que disponen las mujeres para el cuidado. Por otro lado, si bien la extensión del postnatal de 12- 24 semanas incorpora el enfoque de corresponsabilidad del cuidado entre géneros al menos para 6 semanas, al hacerlo opcional, lo transforma en un instrumento de baja aplicabilidad. Aunque es temprano concluir los avances y retrocesos de la reforma, la bajísima participación de hombres ejerciendo el permiso parental indica la necesidad de reforzar mecanismos de tiempo para el cuidado de uso exclusivo para los padres, garantizando un ejercicio efectivo de la corresponsabilidad. Desde la perspectiva de la equidad socioeconómica, la ampliación de las licencias maternales a trabajadoras temporales e independientes constituye una clara medida que mejora las posibilidades de protección social a un importante sector laboral. Sin embargo, las bajas cifras de acceso de estas trabajadoras en el ejercicio efectivo de licencias parentales indicarían que los mecanismos propuestos por la ley resultan al menos engorrosos de aplicar para este grupo. El hecho de que el grueso de las trabajadoras que alcanzan el permiso parental se ubique en estratos de ingresos bajos y medios muestra una distribución progresiva en su uso, en tanto permiso financiado públicamente.

\section{Conclusiones}

El artículo analiza el régimen de cuidados en infancia de Chile, examinando tres instrumentos de provisión: servicios de cuidados a primera infancia, trabajo remunerado y no remunerado dentro del hogar, y tiempo período 2003-2013. A partir de las preguntas formuladas la tabla 4 sintetiza los principales resultados de nuestro análisis.

Tabla 4. Patrón de Cuidados Infancia (0-5 años) Chile, años 2003-2013

\begin{tabular}{|l|l|l|l|l|}
\hline Tipo de Provisión & $\begin{array}{l}\text { Familiarismo/ } \\
\text { Desfamiliarismo }\end{array}$ & Esferas & $\begin{array}{l}\text { Equidad } \\
\text { género }\end{array}$ & $\begin{array}{l}\text { Equidad } \\
\text { socioeconómica }\end{array}$ \\
\hline $\begin{array}{l}\text { Servicios de } \\
\text { cuidados primera } \\
\text { infancia 0-3 años }\end{array}$ & $\begin{array}{l}\text { Desfamiliarización } \\
\text { limitada }\end{array}$ & $\begin{array}{l}\text { Estado } \\
\text { Mercado }\end{array}$ & Maternalismo & $\begin{array}{l}\text { Segmentado: } \\
\text { - Residual (público) } \\
\text { - Contributivo }\end{array}$ \\
\hline
\end{tabular}




\begin{tabular}{|l|l|l|l|l|}
\hline & & & - Mercantil (privado) \\
\hline $\begin{array}{l}\text { Servicios de } \\
\text { cuidados primera } \\
\text { infancia 4-5 años }\end{array}$ & $\begin{array}{l}\text { Desfamiliarización } \\
\text { amplia }\end{array}$ & $\begin{array}{l}\text { Estado } \\
\text { Mercado }\end{array}$ & $\begin{array}{l}\text { Maternalismo } \\
\text { atenuado }\end{array}$ & $\begin{array}{l}\text { Segmentado } \\
\text { - Residual (público) } \\
\text { - Mercantil (privado) }\end{array}$ \\
\hline $\begin{array}{l}\text { Trabajo exclusivo } \\
\text { de cuidados } \\
\text { intrafamiliar no } \\
\text { remunerado }\end{array}$ & $\begin{array}{l}\text { Familiarización } \\
\text { limitada }\end{array}$ & Familia & Maternalismo & Distribución regresiva \\
\hline $\begin{array}{l}\text { Trabajo de } \\
\text { cuidados } \\
\text { intrafamiliar } \\
\text { remunerado }\end{array}$ & $\begin{array}{l}\text { Desfamiliarización } \\
\text { limitada }\end{array}$ & Mercado & $\begin{array}{l}\text { Maternalismo } \\
\text { atenuado }\end{array}$ & $\begin{array}{l}\text { - Contributiva } \\
\text { - Mercantil (Distribución } \\
\text { regresiva) }\end{array}$ \\
\hline $\begin{array}{l}\text { Tiempo para el } \\
\text { cuidado (permisos } \\
\text { parentales) }\end{array}$ & $\begin{array}{l}\text { Familiarización } \\
\text { intermedia }\end{array}$ & Estado & $\begin{array}{l}\text { Maternalismo } \\
\text { atenuado }\end{array}$ & $\begin{array}{l}\text { Contributivo con } \\
\text { distribución progresiva }\end{array}$ \\
\hline
\end{tabular}

Fuente: Elaboración Propia

Referido a la provisión de servicios de cuidados en primera infancia diferenciamos por edades. Para el grupo 0-3 años los datos analizados muestran que el régimen chileno se caracteriza por una desfamiliarización limitada, dado que las tasas de cobertura no superan un tercio de la demanda. La provisión pública y privada no muestra mayores cambios para el período. La modalidad residual (Chile Crece Contigo) para estratos bajos y medios-bajos, contributiva (Derecho Sala Cuna) para mujeres asalariadas y mercantilizada (Privada) para otra parte importante de la población configura un tipo de equidad de género maternalista y socioeconómica segmentada que se refuerzan mutuamente. Para el segundo grupo 4-5 años Chile avanza en forma significativa hacia una cobertura universal caracterizada por una desfamiliarización amplia, donde la provisión por esferas es de carácter mixto (estatal y mercantil). En términos de equidad de género, la alta cobertura de este medio de provisión supone un impacto sobre la estructura de desigualdades de género, atenuando el maternalismo tradicional, porque las mujeres disponen de más oportunidades para compartir y/o traspasar las labores de cuidados hacia otras esferas, aunque sin incidir necesariamente en una mayor corresponsabilidad entre géneros al interior del hogar. A nivel de equidad socioeconómica se observa una asignación de recursos segmentada debido al tipo de provisión del sistema educativo chileno en tres modalidades: público, privado subvencionado y privado, patrón que debería observar cambios a partir de la nueva ley de inclusión.

El trabajo exclusivo de cuidados dentro de hogar no remunerado muestra una importante disminución, aspecto que indica una atenuación del familiarismo, desde un rango intermedio hacia otro limitado. En materia de equidad de género este tipo de provisión, brindada exclusivamente por la esfera familiar y mujeres, mantiene un carácter maternalista. Desde la perspectiva de la equidad socioeconómica se aprecia una distribución regresiva, dado que son los hogares de menores ingresos quienes más recurren a este tipo de provisión, acentuando el familiarismo y el maternalismo en estos estratos. Por otra parte, el cuidado dentro del hogar está representado por trabajo 
doméstico remunerado, que también muestra una disminución, aunque menos que el trabajo no remunerado. Desde la perspectiva de quien brinda estas labores de cuidado, la equidad de género muestra una tendencia de atenuación del maternalismo, considerando la igualación de condiciones laborales entre trabajadoras domésticas y el resto de trabajadores asalariados privados, pero con la amenaza de la neo-domesticidad. La equidad socioeconómica de esta provisión es contributiva porque las trabajadoras domésticas adquieren derechos en su calidad de asalariadas y mercantil, por cuanto el servicio se compra en el mercado. Esta modalidad de provisión observa además una distribución regresiva en dos sentidos: primero, este tipo de provisión es demandado principalmente por hogares de estratos medios y altos; segundo, las mujeres que desarrollan esta actividad remunerada provienen de hogares de estratos bajos y mediosbajos.

Con relación a los cambios operados con permisos parentales para el cuidado, se aprecia un leve aumento en el acceso a este tipo de permisos durante los tres primeros años de aplicación, permitiendo que las personas responsables del cuidado puedan compatibilizar mejor el trabajo remunerado y el cuidado. Si bien esta medida reubica la función del cuidado en la esfera familiar (familiarización), adquiere un carácter acotado o intermedio en la medida que su aplicación es limitada en el tiempo. Junto a lo anterior, otorga protección laboral y refuerza la autonomía económica a las mujeres. El carácter de familiarismo intermedio presente en este mecanismo está acompañado de un rasgo desmercantilizador al ser provista por la esfera estatal. Respecto a la equidad de género, el conjunto de mecanismos de tiempos para el cuidado (maternal, paternal y parental) presentan un rasgo de maternalismo atenuado porque si bien mejoran la corresponsabilidad en relación a la legislación anterior, continúa teniendo efecto mínimo en la participación de los hombres en las labores de cuidado. En materia de equidad socioeconómica observamos que el acceso a este tipo de mecanismos de cuidado es utilizado fundamentalmente por sectores asalariados, otorgándoles un carácter contributivo. Trabajadoras temporales y cuenta propia presentan un acceso marginal. Desde la perspectiva de los ingresos, son las trabajadoras de ingresos medios y bajos quienes hacen mayor uso, mostrando por tanto una distribución de carácter progresiva.

En suma, los datos analizados indican la existencia de una transición del patrón de provisión de cuidados en infancia en Chile para período 2003-2013, desde una variedad de familiarismo explícito caracterizado por bajas tasas de cobertura de servicios de cuidados a la primera infancia, significativa provisión dentro del hogar no remunerada y remunerada, y ausencia de mecanismos de tiempo para el cuidado compartido, hacia un familiarismo opcional, representado por el aumento de la provisión de servicios de cuidados externos, una disminución en la provisión dentro del hogar y la creación de permisos parentales. Es decir, sin abandonar el familiarismo tradicional, el régimen chileno ofrece mayores oportunidades de desfamiliarización que en el pasado. Esta característica merece una distinción: dependiendo del grupo de edad de quienes reciben cuidados, para los más pequeños (0-3) el régimen se encuentra aún en un familiarismo explícito, en cambio para los mayores (4-5) adquiere un carácter desfamiliarizador. 
Además, la variedad de familiarismo es dual, debido a que los estratos bajos y mediosbajos se encuentran más bien dentro del tipo de familiarismo explícito y los estratos medios y altos dentro de un familiarismo opcional. Este patrón de provisión representa una transición en equidad de género desde un maternalismo acentuado hacia otro moderado, pero sin implicar corresponsabilidad. En términos de equidad socioeconómica, el régimen de cuidados mantiene un carácter segmentado, conviviendo una modalidad residual y mercantilizada, y en menor medida una provisión contributiva.

Ahora, ¿qué factores permiten explicar las transformaciones mostradas? Respecto al creciente proceso de desfamiliariazación observado en los servicios de cuidados a niños y niñas de 4 y 5 años, su tendencia estaría más bien asociado a la promoción de mejores oportunidades educativas a la infancia que una búsqueda explícita de aliviar a la esfera familiar de las tareas de cuidado. La ley de obligatoriedad de la educación inicial para niños y niñas de 4-5 años conforma una muestra de esta intencionalidad y esto se explicaría, según Staab (2014) por la herencia maternalista del régimen de bienestar chileno que no termina de superar el patrón tradicional que subyace en estas políticas. Sin embargo, podemos igualmente hablar de una interacción positiva entre una política explícita de ampliación de oportunidades educativas y un proceso implícito de desfamiliarización de los cuidados en infancia para este tramo de edad.

En relación al trabajo doméstico remunerado, el análisis nos indica que este tipo de provisión se ubica entre un familiarismo opcional e implícito a la vez. Opcional porque el trabajo doméstico remunerado representa una forma de provisión de cuidados desde la esfera del mercado a familias de ingresos medios y altos. Es implícito porque esta forma de provisión es limitada a algunos hogares y porque quienes ejercen esta labor tradicionalmente la desempañan bajo condiciones de alta precariedad y sin garantías que les permitan compatibilizar sus necesidades de trabajo y cuidado. Las reformas laborales tienen un efecto que atenúa la precariedad, homologando derechos laborales en igualdad de condiciones al resto de los trabajadores privados. Sin embargo, persiste la amenaza de una neo-demesticidad sostenida por Molinier (2017) basado en el bienestar de unos sobre la servidumbre de otras, sumado el crecimiento de la población migrante femenina en condiciones de mayor vulnerabilidad.

En materia de tiempo de cuidados, éste aumenta para las mujeres, pero sin la necesaria equiparación con los tiempos destinados a los hombres para ejercer estas labores, reforzando el factor de amenaza a la inserción o continuidad laboral de las mujeres en el mercado laboral, porque son ellas quienes asumen los mayores costos asociados a su contratación. Si bien, el aumento de tiempos para el cuidado en términos generales aparece como una política que busca mejorar la conciliación trabajo y familia, observamos la persistencia del paradigma maternalisma que limita una corresponsabilidad más equilibrada entre hombres y mujeres. Falta un aumento de tiempo para el cuidado para los hombres expresado en derechos efectivos, individuales e irrenunciables (CM, 2017). 
Por tanto, el cambio de patrón de provisión de cuidados en infancia desde un tipo de familiarismo explícito hacia otro del tipo opcional no representa necesariamente un abandono del paradigma tradicional y maternalista con el cual Pribble (2006) cataloga al régimen de cuidado de Chile. De allí la necesidad de avanzar en políticas efectivas de ampliación de servicios de cuidados de carácter universal y ciudadano, cambios en la concepción del tiempo de trabajo que incluya tanto labores remuneradas y no remuneradas como un todo, y transformaciones socioculturales tendientes a superar el paradigma tradicional de organización familiar (Torns, 2005). Una aplicación limitada de políticas conciliatorias configura una amenaza al desarrollo y autonomía de las mujeres, dejando circunscritas estas labores sólo a un acuerdo que atañe a la familia y las mujeres. De no mediar políticas más explícitamente desfamiliarizadoras, estaríamos ante el fenómeno de la figura de las "supermujeres" (Moreno, 2002), asumiendo funciones productivas y reproductivas en un contexto de mayor exigencia, y actuando como amortiguadoras de las debilidades del régimen de cuidados. 


\section{Bibliografía}

Aguirre, R. (2007). Los cuidados familiares como problema público y objeto de políticas En I. Arriagada (Ed.), Familias y políticas pública en América Latina (Vol. VIII). Santiago de Chile: CEPAL/UNFPA

Arriagada, I., \& Todaro, R. (2012). Cadenas globales de cuidados: el papel de las migrantes peruanas en la provisión de los cuidados en Chile. Santo Domingo: ONU Mujeres.

Batthyany, K. (2015). Las políticas y el cuidado en América Latina. Una mirada a las experiencias regionales. Asuntos de Género: Vol. 124. Santiago de Chile: CEPAL/Cooperación Española.

BCN, Biblioteca del Congreso Nacional de Chile (2017). Ley 20379 Sistema Nacional Chile Crece Contigo. Recuperado 21.06.2017 desde: https://www.leychile.cl/Navegar?idNorma=1006044

Bedregal, P. (2010). Chile Crece Contigo; el desafío de la protección social de la Infancia. En O. Larrañaga \& D. Contreras (Eds.), Las Nuevas Políticas de Protección Social en Chile. Santiago de Chile: UQBAR

Betancor, A., \& De Martini, M. I. (2012). Detrás de la Puerta. Trabajo, roles de género y cuidado. Santiago de Chile: Comunidad Mujer.

Blofield, M., \& Martínez Franzoni, J. (2015). Maternalism, Co-responsibility and Social Equity: a typology of work-family policies. Social Politics, 22(1), 38-59. doi: http://dx.doi.org/10.1093/sp/jxu015

CEPAL, C. E. p. A. L. y. e. C. (2015a). CEPALSTAT. Retrieved 24.08.2015, from CEPAL http://estadisticas.cepal.org/cepalstat/WEB_CEPALSTAT/estadisticasIndicadores.asp?idio $\mathrm{ma}=\mathrm{e}$

CEPAL, C. E. p. A. L. y. e. C. (2015b). Observatorio de Igualdad de Género. Recuperado de: https://oig.cepal.org/es/indicadores/tiempo-total-trabajo

CM. (2017). Boletín Mujer y Trabajo: protección a la maternidad en Chile, una mirada histórica. Serie Comunidad Mujer, Octubre 2017, 39: http://www.comunidadmujer.cl/biblioteca-publicaciones/2017/10/boletin-mujer-y-trabajoproteccion-a-la-maternidad-en-chile-una-mirada-historica/

Daly, M., \& Lewis, J. (2011). El concepto de "social care" y el análisis de los estados de bienestar contemporáneos. En C. Carrasco, C. Borderías \& T. Torns (Eds.), El trabajo de cuidados. Historia, teoría y políticas (pp. 225-251). Madrid: Catarata 
DT, D. d. T. (2015). Código del Trabajo. Santiago de Chile: Dirección del Trabajo.

ENCLA, E. L. (2012). ENCLA Género 2011. Una mirada a la realidad laboral de trabajadoras y trabajadores. Informe de resultados Séptima Encuesta Laboral. Santiago de Chile: Departamento de Estudios de la Dirección del Trabajo.

Esping-Andersen, G. (2000). Fundamentos sociales de las economías postindustriales. Barcelona: Ariel.

Esping-Andersen, G. (2015). The three world of the welfare capitalism. Cambridge: Polity Press.

Filgueira, F. (2007). The Latin American Social States: critical junctures and critical choices. En Y. Bangura (Ed.), Democracy and social policy (pp. 136-163). Hampshire: Palgrave/UNRISD

Filgueira, F., Gutiérrez, M., \& Papadópulos, J. (2011). A Perfect Storm? Welfare, Care, Gender and Generations in Uruguay. En S. Razavi (Ed.), Sean, Heard and Counted. Rethinking Care in a Development Context (pp. 149-174). Malden: Blackwell doi: http://dx.doi.org/10.1002/9781118297261.

Giménez, D. M. (2003) Género, previsión y ciudadanía social en América Latina. Mujer y Desarrollo. Santiago de Chile: CEPAL.

INE, I. N. d. E. (2015a). Proyecciones de población 2014 Santiago de Chile: Instituto Nacional de Estadística, Chile.

INE, I. N. d. E. (2015b). Mujeres en Chile y Mercado del Trabajo. Participación laboral femenina y brechas salariales. Santiago de Chile: Instituto Nacional de Estadísticas Chile.

JUNJI. (2015). Manual de Programas Educativos Infantiles. Junta Nacional de Jardínes Infantiles. Departamento Técnico.

Leitner, S. (2003). Varieties of familialism: The caring function of the family in comparative perspective. European Societies, 5(4), 353-375. doi: http://dx.doi.org/10.1080/1461669032000127642

Lopreite, D., \& Macdonald, L. (2014). Gender and Latin American Welfare Regimes: Early Childhood Educaction and Care Policies in Argentina and Mexico. Social Politics, 21(1), 80-102. doi: http://dx.doi.org/10.1093/sp/jxt014

Lupica, C. (2015) Corresponsabilidad de los cuidados y autonomía económica de las mujeres. Lecciones aprendidas del permiso postnatal en Chile. Asuntos de Género: Vol. 126. Santiago de Chile: CEPAL/Ministerio de Asuntos Exteriores de Noruega. 
Marcel, M., \& Rivera, E. (2008). Regímenes de Bienestar en América Latina. En E. Tironi (Ed.), Redes, Estado y Mercados. Soportes de la Cohesión Social Latinoamericana. Santiago de Chile: Uqbar

Martinez Franzoni, J. (2008). ¿Arañando el bienestar? Trabajo remunerado, protección social y familias en América Central. Buenos Aires: CLACSO.

MDS. M. d. D. S. (2015a). CASEN 2013 - Educación. Santiago de Chile: Ministerio de Desarrollo Social, Chile.

MDS, M. d. D. S. (2015b). CASEN 2013 Inmigrantes. Síntesis de Resultados. Santiago de Chile: Ministerio de Desarrollo Social. Chile.

MIDEPLAN, M. d. P. (2007). CASEN 2006. Educación. Santiago de Chile: Ministerio de Planificación.

MINEDUC, M. d. E. (2013). Ley № 20.710. Ministerio de Educación, Chile.

MINTRAB, M. d. T. y. P. S. (2014). Ley 20786. Valparaíso, Chile: Biblioteca del Congreso Nacional de Chile.

MINTRAB, M. d. T. y. P. S. (2011). Ley $N^{\circ} 20.545$. Ministerio del Trabajo, Chile.

MINTRAB, M. d. T. y. P. S. (2002). Ley 20399. Código del Trabajo, Chile.

Molinier, P. (2017). Cuidado, vulnerabilidad, víctima. Elementos para una problemática psicosocial. En Gabriel Gatti (Ed.), Un mundo de víctimas. Barcelona: Anthropos

Moreno, L. (2002). Bienestar Mediterráneo y "supermujeres". Revista Española de Sociología(2), 41-56.

O'Connor, J., Orloff, A., \& Shaver, S. (1999). States, Markets, Families. Gender, Liberalism and Social Policy in Australia, Canada, Great Britain and The United States. Cambridge: Cambridge University Press.

Orloff, A. (1993). Gender and the Social Rights of Citizenship: State Polices and Gender Relations in Comparative Perspective. American Sociological Review, 58(3), 303-328. doi: http://dx.doi.org/10.2307/2095903

Orozco, A. (2007). Cadenas Globales de Cuidado. Santo Domingo: PNUD.

Pribble, J. (2006). Women and Welfare. The politics of coping with new social risks in Chile and Uruguay. Latin American Research Review, 41(2), 84-111. doi: http://dx.doi.org/10.1353/lar.2006.0028 
Razavi, S. (2007). The political and Social Economy of Care in a Development Context. Conceptual Issues, Reserach Questions and Policy Options Gender and Development Programme. Geneva: United Nations Research Institute for Social Development

Sauma, P. (2012) Protección social y trabajo no remunerado: Redistribución de las responsabilidades y tareas del cuidado. Estudio de caso de Costa Rica. Mujer y Desarrollo: Vol. 116. Santiago de Chile: CEPAL.

Staab, S. (2013) Protección social para la infancia y adolescencia en Chile. Vol. 180. Santiago de Chile: CEPAL/UNICEF.

Staab, S. (2014). Maternalism, Male-Breadwinner Bias, and Market Reform: Historical Legacies and Current Reforms in Chilean Social Policy. Social Politics, 21(1), 80-102. doi: http://dx.doi.org/10.1093/sp/jxs010

Staab, S., \& Gerhard, R. (2011). Putting two and two together? Early Childhood education, mothers' employment and care service expansion in Chile and Mexico. Development and Change, 42(4), 1079-1107. doi: http://dx.doi.org/10.1111/j.1467-7660.2011.01720.x

SUCESO, S. d. S. S. (2015). Subsidio por permiso postnatal parental 2011-2014. Santiago de Chile: Superintendencia de Seguridad Social.

Sunkel, G. (2007). Regímenes de bienestar y políticas de familia en América Latina. En I. Arriagada (Ed.), Familias y políticas públicas en América Latina. Santiago de Chile: CEPAL/UNFPA

Torns, T. (2005). De la imposible conciliación a los permanentes malos arreglos. Cuadernos de Relaciones Laborales, 23(1), 15-33.

Torns, T. (2008). El trabajo y el cuidado: cuestiones teórico-metodológicas desde la perspectiva de género. EMPIRIA. Revista de Metodología de Ciencias Sociales(15), 5373. doi: $h$ ttp://dx.doi.org/10.5944/empiria.15.2008.1199

Ullmann, H., Maldonado Valera, C., \& Nieves Rico, M. (2014) La evolución de las estructuras familiares en América Latina, 1990-2010. Los retos de la pobreza, la vulnerabilidad y el cuidado. Políticas Sociales: Vol. 193. Santiago de Chile: CEPAL/UNICEF. 